\title{
Innovative undergraduate education strategy
}

\author{
Viktoriya Kuznecova ${ }^{1, *}$, Marina Ivanova ${ }^{1}$ and Elena Starkova ${ }^{1}$ \\ ${ }^{1}$ Moscow Region State University, 10A, Radio str, 105005, Moscow, Russia
}

\begin{abstract}
The article examines various methods of enhancing the undergraduate learning process efficiency through the use of the unique lesson structure based on implementing the innovative teaching techniques such as hackathon and networking allowing students to develop valuable soft skills. The main recommendations for the arrangement of these methods are described. The new types of research sessions such as excursion lessons which include a group laboratory work or research projects are studied in order to improve students' hard skills. The distinctive features of practical discussion classes are considered as well.
\end{abstract}

\section{Introduction}

There is a plethora of sociocultural and economic factors influencing the development of the objectives, content, approaches and techniques of pedagogical process management at universities that determine the significance of finding innovative methods of organizing the undergraduate learning process. Among them, the following factors could be pointed out: the globalization processes as a development trend in the world economy and community [5], the dynamic integration of information technology in all areas of modern society and the resulting changes in the job market, as well as the increasing role of human capital assets in determining the quality of life. "At the turn of the second and the third millennia the society of both adults and children encountered major problems" [10], which still remain unsolved.

Not only did it trigger the change in the Russian educational paradigm at the close of the 20th - the beginning of the 21st century reflected in Federal State Educational Standard of Higher Education (2018). "Given the introduction of the new Federal State educational standards of higher education $3++\ldots$, in which key competencies of a graduate are listed,... which necessitates a review of the methodology applied in the professional training of students" [3]. But it also put forward the requirement to determine the updated methodological basis for the educational process management at the university, including the undergraduate level.

"In order to prepare the students both professionally and pedagogically for the targeted activities in a developing educational environment ... it is of great importance to create an appropriate educational environment of a pedagogical university" [9]. When working on this matter, it is crucial to take into account that "the modern student is fluent in quickly finding the information needed using the Internet... The material traditionally presented by a professor in the classroom is no longer appealing due to the high degree of information

* Corresponding author: kuznetzowa_ve@mail.ru 
accessibility. A student is not intent on listening carefully, let alone understand the material that is part of his professional training. Beyond doubt, this has a negative impact on the effectiveness of the study of a particular academic discipline as well as on the overall quality of vocational education. As a consequence, there is an urgent need of applying a systematic activity approach to the arrangement of a pedagogical process at universities, as well as finding a functional method of educational management" [6].

All stated above results in the problem of defining the spectrum of extracurricular knowledge, skills and competencies required for students to graduate from the educational institution so that they could smoothly adapt to the workplace" [6]. The discovery of undergraduate teaching methods based on this spectrum, as well as the disclosure of pedagogical conditions allowing to employ it could not only increase the learning process efficiency, but also to form a successful person. Constantly developing oneself, such person would be able to find a place in the quickly-changing modern labor market, as well as a place in society by building proper relationships. "Solving the problems described is quite a challenging and lengthy process" [11].

\section{Materials and Methods}

The research was conducted on the basis of a combination of systemic, activity-based and multi-subject approaches. This implied the study in terms of correlation between the components of a pedagogical process (learning objectives, contents, approaches and techniques) and a student's activity which defines personal development. The subjects of the educational process were examined within the context of the relationships formed between them. Their activity served as a strategy for the appropriate transformation of the surrounding environment model.

The following methods and techniques were applied for this research:

$>$ general scientific methods including generalization and specialization, analysis, synthesis, comparison, inductive and deductive approaches, modeling, as well as some theoretical methods comprising literature review, fundamental research concepts analysis, causal research on studied phenomena, forecasting;

$>$ empirical methods covering data collection (observation, interview, questionnaire, survey, examination of documents, products of professors' activity and experience), evaluation (self-assessment, ranking, academic discussion), monitoring and measurement (scaling, cuts, tests), studying educational process taking into account precise modified conditions (pedagogical experiment and experimental check of the research findings in terms of a university environment), processing of data (mathematic: static, graphic, tabular).

The experimental basis of the research under discussion was provided by the faculties of Moscow Region State University: the Faculty of Special Pedagogy and Psychology, the Faculty of Psychology and the Faculty of Roman and Germanic Languages of the Institute of Linguistics and Intercultural Communication.

The experimental group consisted of students of the Faculty of Special Pedagogy and Psychology (427 students of the 1st and the 2nd years of study, including 307 students of the on-site education and 120 students of the off-site program). The control group consisted of students of the Institute of Linguistics (258 on-site students of the 1st year of study) and of students of the Faculty of Psychology ( 84 on-site students of the 2nd year of study).

In the course of the experiment, the developed general concepts for lesson planning based on the use of innovative forms of education were tested, which led to distinguishing some features of networking and hackathon as forms of training for the undergraduate students during the study of Pedagogy (a general discipline presented by the Federal State Educational Establishment of Higher Education),. Furthermore,during the experiment, 
several pedagogical conditions for conducting practical research classes were discovered. As part of the research classes, the criteria for the efficiency of a group laboratory work and research projects were clarified.The experiment was carried out in three stages.

The first stage (the academic years of 2015-2016 and 2016-2017) allowed to prove the possibility of organizing classes in an innovative form, subject to a number of pedagogical conditions. These conditions include the students' desire to cooperate with a professor and each other, the willingness of the faculties' management structures to take into account the need to comply with the sequence of the academic hours devoted to the study of discipline through the use of the same educational form in the scheduling. Moreover, the first stage of the research revealed that it is acceptable to use not only the material and technical sources of Moscow Region State University, but also the sources of museums (Museum of Education History, Museum of Industrial Culture, Museum of The USSR, Museum of Russian Icon painting), libraries (Russian State Children's Library, Library of Foreign Literature, Central Scientific Library), cultural and historical centers (VDNH, Zaryadye Park, Moscow Hermitage Garden), and other universities (RANEPA, Moscow State University of Printing Arts, Russian State University named after A.N. Kosygin, Russian State Social University).

At the second stage (the academic year of 2018-2019) the order structure of the innovative classes types was adjusted, allowing to improve the quality of the educational process and contributing to the development of hard skills and soft skills among the undergraduate students.

At the third stage (the first term of the academic year 2019), the system of effective methods for the innovative education strategy implementation was approved. In particular, it was revealed that the collage method allows students to visualize the theoretical concepts studied at the beginning of a course of an academic discipline. The student's speech supported by a self-made collage helps to quickly build cognitive interrelations in the material studied, as well as to classify and summarize the knowledge gained.

The statistical data showing the development of soft-skills and hard skills in the experimental and control groups are presented in the Figure 1.

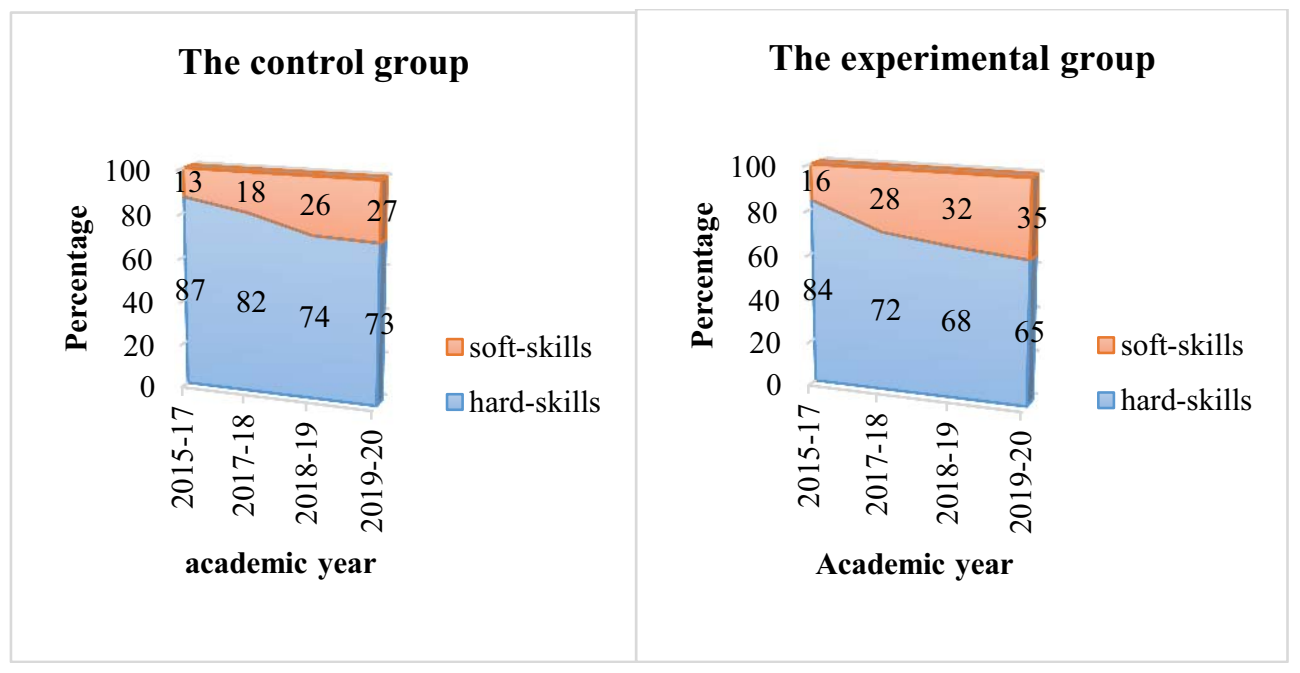

Fig. 1. The development of soft-skills and hard skills in the experimental and control groups. 


\section{Results}

The results of the scientific research confirmed the approved course structure of the discipline of Pedagogy, displayed in Figure 2, which is designed for 12 hours of lectures and 24 hours of practical training per semester.

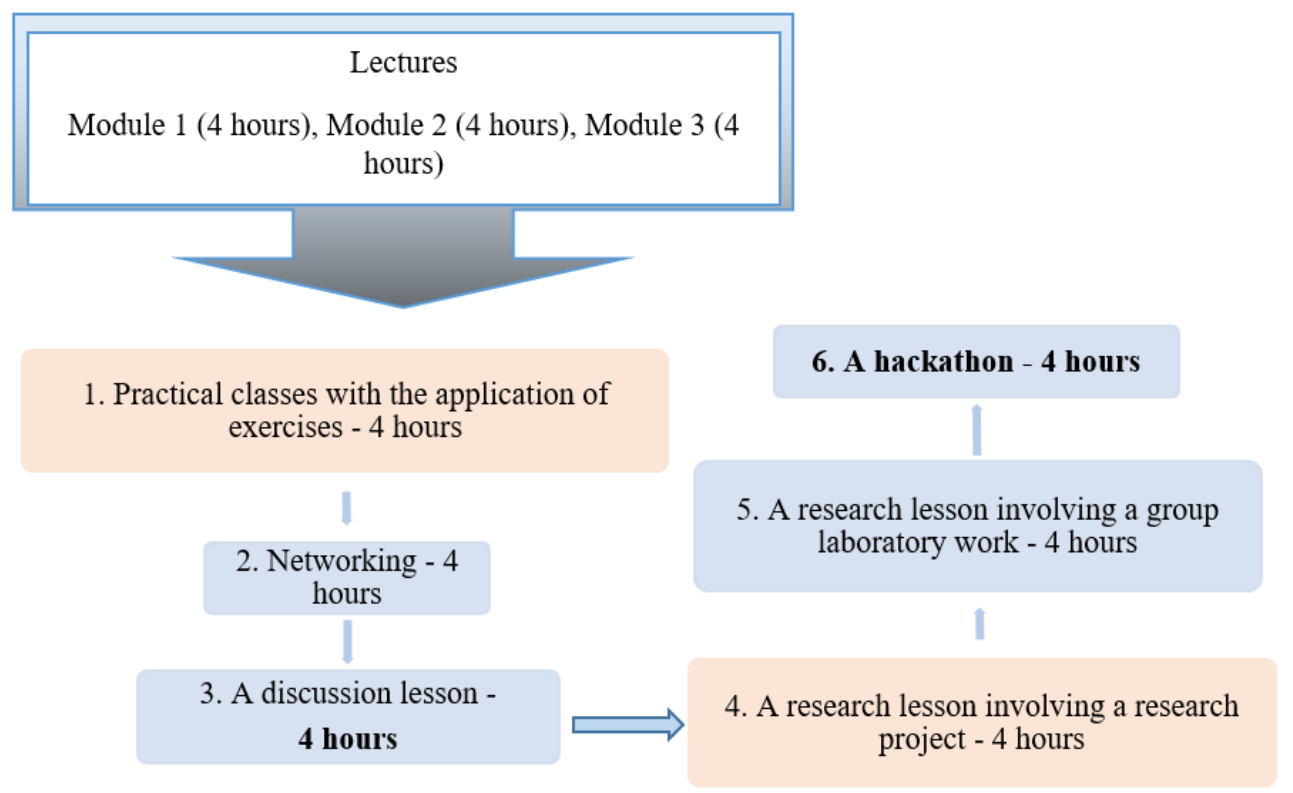

Fig. 2. The structure of the Pedagogy course.

The detailed structure of each class designed for 4 hours is considered. The major requirement for the successful practical classes is the lecture material provided by the professor in advance (for example, the text of the lectures as well as presentations supporting the lectures uploaded on the educational website of the university).

1. The purpose of a practical class with the application of exercises is to create the culture of communication and the development of empathy. The structure of the class under discussion includes four exercises.

At the beginning of this lesson, students learn to observe which enables the development of empathy and skills required for a project work. In the first exercise, the professor gives the students a task to analyze photos depicting people interacting with each other. The analysis structure implies the detailed answer on each item of a question plan presented below:

- what do I see?

- what do people in the photo feel?

- what happens to these people, what event do they take part in?

The professor should pay special attention to the precise plan performance in order to teach students to reasonably assess the communicative situation, without adhering to stereotypes when analyzing the surrounding environment.

The next exercise serves to realize that there are absolutely no good or absolutely bad people. In addition, it inspires the elimination of communicative barriers.

Each student is asked to write down 5 positive and 5 negative traits of his/her character, and then read the list out loud, allowing explanations of the traits written. After all students of the class delivered their reports, the professor emphasizes the fact that some students have the same qualities written in different lists. The professor points out the subjectivity 
and the complexity of the attitude that people form towards others, and underlines that it could interfere in meaningful communication.

Afterwards, the students are invited to participate in the exercise called "Sketch". In this work, students are divided into groups consisting of three people. Each group chooses a topic to discuss. The group members choose the least appropriate for their personalities role to play in the process of communication: "Rationalist" is prone to support his judgment with arguments when discussing problems, "Accuser" usually looks for guilty parties, "Conformist" tend to copy the behavior of people in the group. At first, the conversation takes place only between group members, and then each group is given the opportunity to demonstrate their discussion in front of the others. When the participants finish their performance, the professor suggests guessing the particular roles chosen by each student. Most commonly, this presents a challenge. The professor draws the students' attention to the fact that it was difficult for the performers to display an unusual style of behavior. It is important to underline the need to form the ability to consider the problem from the perspective of another person. It is undoubtedly crucial to interpret the other people's point of view instead of immediately demand the understanding from them.

The fourth exercise is called the "Perfect teacher" speech, which allows each student to form a professional and creative self-image. This task involves the application of the collage method in order to visualize the associative bondsbetween the material that was considered at the lectures and the practice session's content. The task consists of making a short speech on how each student pictures the ideal teacher, illustrating the main talking points with the use of a collage (the students are provided with photos from magazines and newspapers, scissors, paper, markers and glue in advance). The speech must include at least 6 terms studied at the lecture of the first module. The terms must be used in correlation with the problems discussed during the practical lesson. After that, students are invited to make a presentation to the group. Each student has three minutes to express the discussed opinion supported by the collage made (a timer is set at the beginning of every speech).

Thus, this class allows to form the basics of the communicative culture, which is an integral part of soft skills, as well as to develop hard skills underlying the professionalism in the implementation of general concepts of interrelations between theory and practice.

The next element in the structure of the course contributes to the transition of the "pedagogy of responsibility" [1].

2. This type of activity is called networking. It is known that networking activity implies the gathering of people contributing to the effective solution of complicated life or professional problems. The necessary skills related to the creation of a social network of people who are significant in the context of society by an individual, are based on a "six degrees of separation" theory. This theory was developed in terms of Microsoft's analysis of data shared by approximately 2.5 million users, which revealed the possibility of "reaching" any user in 6.6 social connections. This proved that the development of skills of establishing relationships with socially valuable people is immensely important. This work is aimed to form the network of the described relationships not only indirectly (with the use of social networks such as Instagram or Facebook), but also in the process of different activities. In the interview with Forbs [14], Andrej Sharonov, the president of Moscow School of Management Skolkovo, emphasized the value of the skills under discussion pointing out the role of human capital in the development of both society and economy. Moreover, he stated that"we should be able to build relationships, we should be able to manage the work of a team, we should be able to doubt everything including the information supported by the key opinion leaders and we should believe that we can make a difference". 
In the scope of the educational process, networking is a form of students' activity, enabling the development of skills related to the selection of socially valuable people who contribute to the solution of a professional problem.

The learning process of establishing the relationships involves several steps.

At the first step, the class is divided into the small groups of 5-6 people, so that there are 5 groups total. Each group receives a text to be analyzed. When studying the Pedagogy course, students learned the fundamental principles in didactics, as well as the theories of education presented by famous professors. Their task was to find strengths and weaknesses in the concepts considered. This ensured not only the formation of hard skills, but also the development of soft skills within the framework of a communicative culture.

At the second step of networking, students were required to communicate with representatives of other groups chosen randomly, and to identify the strengths of different concepts basing on the exchanged information. This process instigated the formation of the skills related to the selection of individuals, whose opinion could be valuable for solving professional problems.

At the third step of the activity, the groups had to get rid of their concept's shortcomings that were identified at the first step of the class practice. This task was completed through the application of solutions adopted from different concepts of other students.

At the fourth step, each group prepares a collage illustrating the solution, and a threeminute speech describing it. The collage method allows to visualize the associations that evoke when working with theoretical material.

At the fifth step, the approach developed by a group is defended by its leader in front of the entire class. The members of the group who prepared the decision together are entitled to supplement and correct the speaker. All members of the group are given the same grade which affects its cohesion and the ability to work successfully in a team.

Therefore, while performing the communicative interactions on the content of the discipline, students continue to form hard skills, as well as soft skills that are directly related to the "multicultural world view" [8].

3. The discussion lesson is conducted based on a group work.

The class is divided into two teams. Each team is provided with a problem to reflect on by a professor. During the Pedagogy course, these were controversial pedagogical situations that allowed an ambiguous assessment of the environment at issue.

Then the floor is given to a representative of each team for a substantiated introduction of the decision found. Afterwards, each team discusses the benefits and drawbacks of the opponents' findings and makes adjustments to their own decision. The speaker announces the solution developed by the group. Subsequently, an open discussion stage begins, the main rule of which is: "The floor is given only to one person at once and the offensive personal comments towards the others must be avoided".

The lecturer summarizes the outcomes of the discussion, emphasizing the crucial importance of reaching a consensus.

4. A research lesson implies the completion of a project and is designed to combine individual achievements to deliver results of a group work. Two methods of a lesson realization have been tested.

The first method features students preparing a presentation at a scientific conference on independently chosen topics that are related to the discipline studied. During the lesson, the topics selected by the students were combined in three or four groups. Each student made the presentation on the research topic in front of the group members. The group members graded the speaker based on the criteria set by the professor: each speech must not exceed three minutes; the content of the presentation must be relevant to the topic; the report must include a well-founded reflection of the author on the solution of the problem under consideration. On the basis of the presentations, the students wrote a summary of the work 
of the group, which was outlined by a group representative at the end of the conference. The other groups' participants could ask the representative questions related to the problem discussed. All members of the group were given the same grade, grounding on the speaker's ability to present the results and suggestions of the group, as well as to answer the questions posed by other students.

The conclusion of the conference was drawn by the professor, underlining the importance of listening to the opinion of the others.

The second method of the research lesson delivery involves going on a field trip to museums, libraries, exhibitions and city festivals. The students select the material that would help them to solve the educational tasks set by the professor. For instance,during the Pedagogy course, such lesson was devoted to the search for effective means of the pedagogical process organization. The museum excursion encouraged students to identify the exhibits that could be used in class with children. During a subsequent group discussion, the discovered and classified tools for education or upbringing allowed to plan a lesson with children. The students set the objectives of the lesson, as well as selected the most effective methods of organizing it based on the group opinion. The final group work was completed by the end of the field trip and presented at the next lesson for discussion. It is crucial to remember that "the excessive attention to mistakes without discussing how to overcome and prevent them encourages a one-sided reflection of a pedagogical reality in the minds of students" $[12,15,16]$. Therefore, it is important to draw students' attention to the suitable decisions and helpful findings during a research project.

5. A research lesson involving a group laboratory work is an independent lesson, closely related to the previous exercise.

In this lesson, students study the actual examples of their professional activities. During the Pedagogy course, students listen to the audio materials of various children's fairy tales ("Tales from Moominvalley" by Jansson T. ), as well as analyze the fragments of different literary works ( "Jane Eyre” by Brontë Ch.,"Grown-ups Don't Understand” by Irmgard K.) and scenes from famous films ("Urokifrantsuzskogo","The Adventures of Elektronic") related to children's life situations. By combining individual and group works, students classify the material analyzed based on the theoretical material delivered during the lectures, and assess the efficiency of the pedagogical tools demonstrated.

The next stage of the lesson involves the discussion of the results of the research group project created on the ground of the selection of the empirical material during the previous lesson. In addition to the professional competencies, students also gain the ability to listen to the others, to negotiate and to control the emotions.

6. A hackathon is held as a final lesson that allows to structure professional knowledge and to reinforce hard skills and soft skills. It is widely known that hackathon is becoming an increasingly common type of event involving software experts to cooperate with each other in order to solve a problem. The focus of this "programmers' sprint" is set by the presentation of the event and its specific topics. Offering various ideas, participants form teams based on individual interests and skills. Thereafter, the work on projects takes place, culminating in the demonstrations of results. Sometimes a contest takes place and judges select the winners. A hackathon is considered as a meeting place for professionals to build social networks that bring together talented and active people with common interests. The training is extremely dynamic due to the creative working process, the casual concept of the event and the ability to apply the new knowledge in practice.

The training session suggested in the form of hackathon is similar to a discussion lesson, as it involves the division of students in two opposing groups, but this is a different form of training, since it has distinctive didactic and educational objectives.

When studying Pedagogy at the first stage of work, the class is split into two teams. With the use of the materials provided by the professor and the resources from the Internet, 
each team studies the same modern pedagogical technology, revealing its strengths and shortcomings. During the discussion, each team concentrates on improving the proposed technology. The students are allowed to use "the innovative printed materials that present teaching information in various forms and manage educational activities" [2]. Afterwards, representatives of the teams describe the concept of the technology considered and the approaches to its improvement. Thereafter, each team analyzes the opponents' point of view on solving the problem, as well as reveals the disadvantages of their methodology that are discussed during an open discussion. The result of the work is the applicable technology which includes the advantages found by the participants of both teams.

Consequently, a hackathon develops the creative initiative of students, encourages them to understand professional problems at a new level, and also demonstrates the role of cooperation in finding solutions.

\section{Discussion}

The results of the study could help to improve the efficiency of the university educational process not only in the study of Pedagogy but also in other disciplines. The consideration of the order structure of different forms of classes, as well as the discovery of "the concepts that contribute to the increasing level of perception of educational material" [3, P.60] and the selection of methods and contents of educational process in accordance with the established objectives, allow to teach students disregarding weak motivation to the educational activities. "In the context of the innovative strategy... it is expected to develop not only a person possessing knowledge and skills in a certain field of activity, but also a creative individual capable of learning throughout a lifetime". [13, P.62].This points out the opportunity of training a specialist with soft skills and hard skills who is able to compete in a rapidly changing labor market, and, therefore, a successful person. Thus, the practical significance of the study is determined by the potential to influence the development of human capital and is advantageous for the society and the state.

\section{Conclusions}

The findings of the study are expected to be thoroughly examined within the context of psychology and sociology, in order to describe the impact of a combination of systemic, activity-based and multi-subject approaches to the formation of personality and social relationships.

\section{Acknowledgments}

Deepest appreciation and gratitude are extended to the employees of the dean's office of the Faculty of Special Pedagogy and Psychology at Moscow Region State University, who createdfavorable conditions for conducting the experiment.

\section{References}

1. V.V. Voronov, Vestnik Moskovskogo gosudarstvennogo oblastnogo universiteta. Seriya: Pedagogika 2, 33 (2008)

2. V.V. Voronov, Vestnik Moskovskogo gosudarstvennogo oblastnogo universiteta. Seriya: Pedagogika 4, 23 (2010)

3. N.A. Gorlova, Materialy Mezhdunarodnojnauchno-prakticheskojkonferencii 
«Professionalizmpedagoga: sushchnost', soderzhanie, perspektivyrazvitiya» (M., MGOU, MANPO, Yaroslavl', Remder, 2019)

4. M.E. Ivanova, Vestnik INZHEKONa. Seriya: Gumanitarnyenauki 4, 60

5. V. Kuznetsova, Network form of implementation of the Bachelor and the Master educational programs at a professor's training college (Muenchen, LINCOM GmbH, Hansjakobstr, 2017) ISBN 9783862888443

6. V.E. Kuznecova, «Nauka na blago chelovechestva - 2018», Sbornik nauchnyh statej prepodavatelej $i$ aspirantov po itogam Mezhdunarodnoj nauchnoj konferencii molodyh uchyonyh, aspirantov i studentov (2018)

7. A. Mottaeva, N. Kalinina, A. Kuzmina, O. Olenina, A. Glashev, E3S Web of Conferences 91, 08072 (2019) doi.org/10.1051/e3sconf /20199108072

8. N.A. Suhova, Nauchnoemnenie 3, 142 (2013)

9. P.A. Hromenkov, Nauka i shkola 2, 17 (2014)

10. P.A. Hromenkov, Nauka i shkola 6, 15 (2006)

11. G. Dyakova, S. Izmaylova, A. Mottaeva, E. Karanina, IOP Conf. Series: Earth and Environmental Science 90, 012218 (2017) doi:10.1088/1755-1315/90/1/01221812

12. T.A. Yuzefavichus, Vestnik Moskovskogo gosudarstvennogo oblastnogo universiteta. Seriya: Pedagogika 2, 49 (2010)

13. L.V. Yurkina, O.A. Vol'nyakova, Vyssheeobrazovanie v Rossii 6, 62 (2010)

14. Forbs: "My prevratimsya v kiborgov». Andrej Sharonov o budushchem obrazovaniya https://www.forbes.ru/finansy-i-investicii/380885-my-prevratimsya-v-kiborgovprezident-biznes-shkoly-skolkovo-andrey

15. V.I. Dobrosotskiy, G.N. Semenova, E.B. Kazarinova, N.V. Falina, On the Horizon 27(3/4), 213 (2019) https://doi.org/10.1108/OTH-07-2019-0035

16. A.V. Bataev, A.A. Gorovoy, A.B. Mottaeva, Proceedings of the 32nd International Business Information Management Association Conference, IBIMA 2018 - Vision 2020 (2018) 